\title{
KABBALAH: ON SPATIO-TEMPORAL DATABASE VISUALIZATION WITH HISTORICAL EVENTS: A CASE STUDY OF HISTORY FLOW OF CHIA-YI BEIMEN STATION
}

\author{
T. W. Hsu' ${ }^{\mathrm{a}}$ S. C Chiou ${ }^{\mathrm{a}}$, J. H. Lee ${ }^{\mathrm{b}}$ \\ ${ }^{a}$ National Yunlin University of Science and Technology, Yunlin, Taiwan - (g9830812, chiousc)@yuntech.edu.tw \\ ${ }^{\mathrm{b}}$ Korea Advanced Institute of Science and Technology, Daejeon, Republic of Korea - jihyunlee@kaist.ac.kr
}

KEY WORDS: Spatio-Temporal Database, Historical City, Information Visualization.

\begin{abstract}
:
This system is made for researchers who study pattern of city or spatial transformation by using computational way to interpret data logically. In order to make use of all historical data with GIS in system, an exact metadata is necessary and needed to build first. The Cubism project is aimed to presume how different historical data normalized to become information in spatio-temporal database. To make temporal map have higher capability with presentation of history context.
\end{abstract}

\section{INTRODUCTION}

\subsection{Motivation}

A city formed with numerous classes of historical events. However these records can not completely describe a timespace subject of one city. There are some methods to present historical events by combining with timeline or GIS to present its order or distribution position. But to sense and understand one city only according to single dimension of time or spatial is not objective enough.

A historical research depends on reading lots of historical data to know well with the target which research focus on. This progress is not only time consuming for researchers who reading history, but also can not avoid to collect wrong information.

With the same reading behavior, reading a hypertext is more strength than a linear one. (Chen, 2000). For instance, a GIS map accompanied with occurrence order to translate events information into hypertext or even hypermedia. If the traditional behavior combines with these computational methods, to understanding the historical background of one space will be more efficient.

\subsection{Purpose}

The main purpose of this study is using a symbol system to represent the time-space subject. A conceptual and iconify system may be applied to comprehend the duration of development process. A specific time-space flow will be viewed when focus one target or set rules for seeing complete picture of this city's history. Here are the two goals of this system:

1. To get the biography of one target: Different events may have relationship with each other. By using texts can not present the context of history clearly.
2. To compare individual with others: Multiple dimensions are hard to interpret or make a contrast. The individuals must differentiate before comparing with each other.

\section{LITERATURE REVIEW}

\subsection{Time Geography}

"Time and space" is an indivisible unity. In social culture domain, a space issue should be discussed with history. Time is generated by interaction of society in one space. What people see the development of society is the objective definition for time and space.

During a period of time, space or buildings may change by events. These changes are considered as the attributes of timespace subject. If these changes didn't influence the existence of time-space subject, the new subject may treat as the continued subject for this space. This calls material continuity.

Events may include changed attributes of subject with a series orders. Time is able to measure these orders by defining measurement, like known units such as year, month, day, hours, minute, and second. (Robert Levine, 1997)

Events or facts occurred in past are hard to trace back. Even the most advanced technology is not able to record all attributes of all objects in a city at the same time.

\subsection{Temporal Database}

For a systematic way to record events and changes, Space-Time Composites Model (STC) used to ameliorate the snapshot record model. STC model separates components are about to change, as Figure 1 shows, the relationship between rural and urban. The basic units of this model are the components divide by changes. This model need only to save the value of attributes for these changed components and may solve the consuming problem with working hours and resources. The specific 
component may be helpful for tracing the different units in not the same time. However, this way still has a potential problem. All the components have to redefine when one space changed. This model is not suitable for constantly inputting data. (Langran \& Chrisman, 1988)

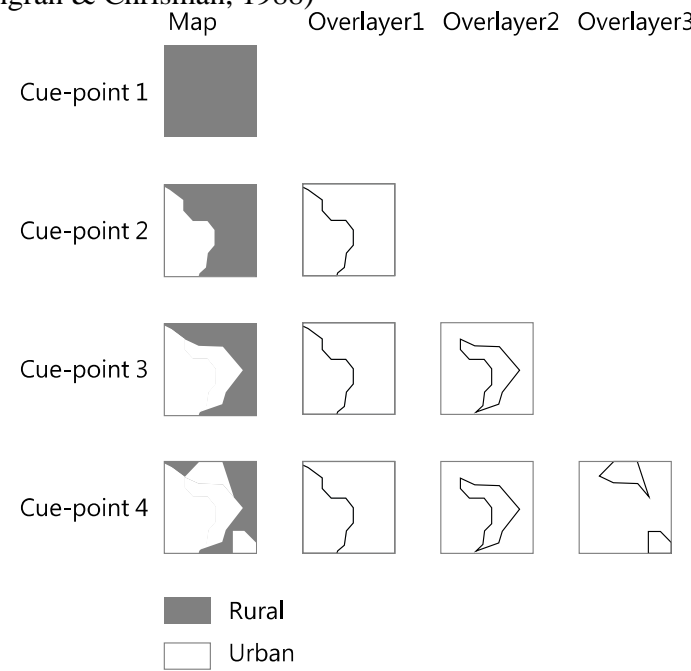

Figure 1. Observing changing between rural and urban in different time

(from Langran, Chrisman, 1988, redraw by this study )

Peuquet and Duan (1995) proposed Event-based Spatiotemporal Data Model (ESTDM) for processing temporal information. By storing events as a unit of temporal data, these information can be integrated with spatial information, and unfold on map.

Leslie mentioned about one temporal data would descript as temporal information (when), spatial information (where), and non spatio-temporal information (what changed). (Leslie, C., Barnes, G., Binford, M., Smith, S., 2001)

The contribution of temporal database for history research includes:

(1) To understand the rules that govern changes observed in the world;

(2) To explain the state of the world at some earlier time;

(3) To predict the state of the world in the future; and

(4) To plan a sequence of actions that will lead to a desirable future.

These four points make urban development research be able to observe the future trends form evolvement, and adjust the plan or strategy of one city.

\section{METHODOLOGY}

The memories of one city's development are hided in historical buildings in this city. People may use these historical buildings to be junctions connect past and present (as Figure 2). As historical building play a role of objective subject, this way makes observing the development of entire city by examining every historical event that this historical building experienced see the changing of space in multiple aspects.

1. Expound existence and essence of temporal map.

2. Plan metadata and normalization of spatio-temporal database
3. Put historical events data of Beimen station into spatio-temporal database

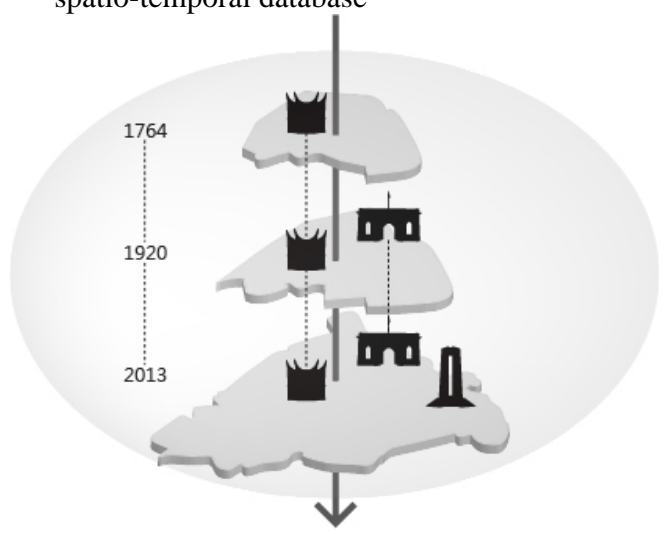

Figure 2. Historic building used as the interface from past to current

\subsection{Definition}

1. Subject: The highest level of space-rank can be separate into many sub objects, like a time-space subject. The subject in this study is referred to timespace subject Chiayi, the historic city.

2. Object: A building, an area, or an organization can be called an object. Objects composite subject, and there are subordinative relationships between objects, like government and its department, or a building in one city area.

3. State: To emblem an object existing. Attributes changed bring about a new state.

4. Event: To change attribute of object, and connect two states. A historic event with text can be presented as an event data.

5. Temporal data: The basic element in space-time model, which composite by two states and one event.

\section{PRIMARY RESULT}

The cue-point represents something changed, but it not means all this building or space make a reconstruction. Evan a small part repaired or the function of this building had been changed, these are able to be called "variation."A symbolic represent system may help to present different variation.

By using structure of timeline, every single attribute has its subtimeline. As any attribute of a subject changed, one of a subtimeline shows a cue-point, and the main timeline may present the same particular time. For one subject, its state is stationary between two cue-points of timeline in different time. Every change of an attribute of one subject should mark a cue-point, and also there are multiple attributes changed probably. As Figure 3 shows below: 


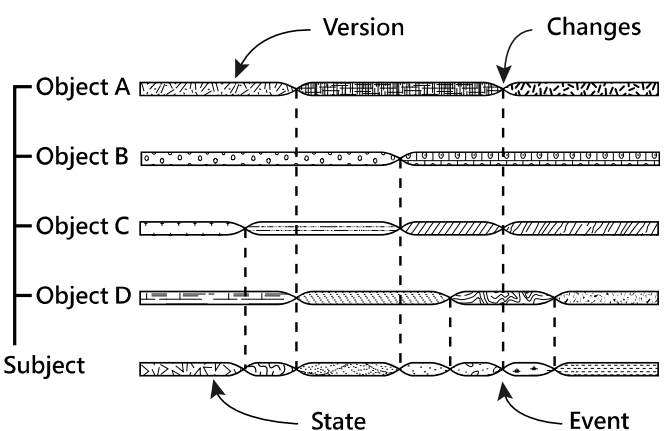

Figure 3. The state of object and the relationship between object and subject (from Langran, G., Chrisman, N., R., 1988, redraw by this study )

Type class includes event type, action, and complement. Events type are classified to "social dynamics"(SD) which people cause environment they live changed, "disaster damage” (DD) which natural phenomena makes object transform, "territorial features”(TF) which are initial conditions of space for defining the original state in the beginning of timeline, "urban policies”(UP) which are supervisors or strategies make city change. Complement is supplement for describing which not mentioned from above metadata.

In order to trace not only current value, but also changes in multiple cue-points, attribute class notes changed item, and the value changed before and after. If there are multiple attributes changed in one event, these data should log in multiple and sequentially way also for recording totally. The value records are helpful for observing if there is any other event not logged. For instance, if there are two cue-points of timeline, and the new (after) value of the first cue-point is not the same as the original (before) value of the second point, this proves some events happened between these two cue-points and make things change. The values in different time can inspect the processing of one subject or one object in period of time. The record class notes established time and establisher, or modified information of this data.

These events data can be connected with the target descriptions, and generated historic events chain. The historic events chain combined with vertex (event) and edge (relationship). Like directed graph (or Digraph) in graph theory, every relationship has its "cause" and "effect" with sequential. The after events are not able to affect the previous ones. In other words, the start node and end node of one edge will not be the same. The "loop" will not possible to appear in one vertex, and "cause" can not be "effect" at the same time. For these rules, the historic events chain will present as a simple graph.

There is relevance between the four event types mentioned above. One event could be the cause of any other events, but kinds of event types can not give rise to other kinds of event type. There are initial rules for these events combining into chains. Like urban policies and social dynamics type could not cause a disaster damage type event. On the contrary, a disaster damage type event may bring about the policies or social changes. However, social dynamics type event will be influenced by other three types. (as Figure 4) The events related to Beimen station list in Table 1 as below:

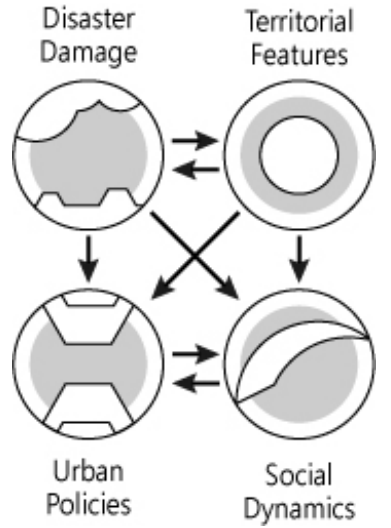

Figure 4. The influence relationship between four types of events

\begin{tabular}{|c|c|c|c|c|}
\hline Year & Initiators & Action & Recipients & Type \\
\hline 1723 & $\begin{array}{l}\text { Qing Dynasty } \\
\text { government }\end{array}$ & build & Beiman gate & UP \\
\hline 1899 & $\begin{array}{l}\text { Japanese colony } \\
\text { government }\end{array}$ & discover & Alishan Forest & UP \\
\hline 1906A & $\begin{array}{l}\text { Japanese colony } \\
\text { government }\end{array}$ & transform & Japanese builders & UP \\
\hline 1906B & $\begin{array}{l}\begin{array}{l}\text { Japanese } \\
\text { builders }\end{array} \\
\end{array}$ & open & $\begin{array}{|ll|}\begin{array}{l}\text { Alishan } \\
\text { railway }\end{array} & \text { forest } \\
\end{array}$ & UP \\
\hline 1908A & $\begin{array}{l}\begin{array}{l}\text { Japanese } \\
\text { builders }\end{array} \\
\end{array}$ & open & $\begin{array}{|ll|}\begin{array}{l}\text { Alishan } \\
\text { railway }\end{array} & \text { forest } \\
\end{array}$ & UP \\
\hline 1908B & $\begin{array}{l}\text { Japanese } \\
\text { builders }\end{array}$ & build & Beimen station & UP \\
\hline 1909 & $\begin{array}{l}\begin{array}{l}\text { Japanese } \\
\text { builders }\end{array} \\
\end{array}$ & transform & Alishan sagyousho & UP \\
\hline 1910A & $\begin{array}{l}\text { Alishan } \\
\text { sagyousho }\end{array}$ & open & $\begin{array}{|ll|}\begin{array}{l}\text { Alishan } \\
\text { railway }\end{array} & \text { forest } \\
\end{array}$ & UP \\
\hline 1910B & $\begin{array}{l}\text { Alishan } \\
\text { sagyousho }\end{array}$ & enable & Beimen station & UP \\
\hline 1912A & $\begin{array}{l}\text { Alishan } \\
\text { sagyousho }\end{array}$ & open & $\begin{array}{|ll|}\begin{array}{l}\text { Alishan } \\
\text { railway }\end{array} & \text { forest } \\
\end{array}$ & UP \\
\hline 1912B & $\begin{array}{l}\text { Alishan } \\
\text { sagyousho }\end{array}$ & enable & \begin{tabular}{|ll}
$\begin{array}{l}\text { Beimen } \\
\text { factory }\end{array}$ & repairing \\
\end{tabular} & UP \\
\hline 1913 & $\begin{array}{l}\text { Alishan } \\
\text { sagyousho }\end{array}$ & enable & Erwanping Station & UP \\
\hline 1914A & $\begin{array}{l}\text { Alishan } \\
\text { sagyousho }\end{array}$ & open & $\begin{array}{|ll|}\begin{array}{l}\text { Alishan } \\
\text { railway }\end{array} & \text { forest } \\
\end{array}$ & UP \\
\hline 1914B & $\begin{array}{l}\text { Alishan } \\
\text { sagyousho }\end{array}$ & enable & \begin{tabular}{|l} 
Chia-Yi material \\
factory
\end{tabular} & UP \\
\hline 1918A & $\begin{array}{ll}\begin{array}{l}\text { Alishan forest } \\
\text { railway }\end{array} \\
\end{array}$ & service & Passenger train & SD \\
\hline 1918B & 1918A & service & $\begin{array}{l}\text { Mountaineering } \\
\text { people }\end{array}$ & SD \\
\hline 1925 & \begin{tabular}{|l} 
Alishan \\
sagyousho
\end{tabular} & enable & $\begin{array}{|ll|}\begin{array}{l}\text { Timber storage } \\
\text { pool }\end{array} \\
\end{array}$ & UP \\
\hline 1933A & $\begin{array}{ll}\begin{array}{l}\text { Alishan forest } \\
\text { railway }\end{array} \\
\end{array}$ & set up & New trunk & UP \\
\hline 1933B & 1933A & service & People & SD \\
\hline 1942 & $\begin{array}{l}\text { Alishan } \\
\text { sagyousho }\end{array}$ & transform & $\begin{array}{l}\text { The } \quad \text { Taiwan } \\
\text { Development Co., } \\
\text { Ltd. }\end{array}$ & UP \\
\hline 1947 & $\begin{array}{l}\text { The Taiwan } \\
\text { Development } \\
\text { Co., Ltd. }\end{array}$ & transform & Forestry Bureau & UP \\
\hline 1950 & $\begin{array}{ll}\text { Alishan forest } \\
\text { railway }\end{array}$ & set up & $\begin{array}{|ll|}\begin{array}{l}\text { Cane } \\
\text { trains }\end{array} & \text { transport } \\
\end{array}$ & UP \\
\hline 1960 & $\begin{array}{ll}\text { Alishan } & \text { forest } \\
\text { railway }\end{array}$ & service & Transport package & SD \\
\hline
\end{tabular}




\begin{tabular}{|l|l|l|l|l|}
\hline Year & Initiators & Action & Recipients & Type \\
\hline 1970 & $\begin{array}{l}\text { Alishan forest } \\
\text { railway experienc } \\
\text { e }\end{array}$ & Golden age & SD \\
\hline 1973A & Forestry Bureau & open & $\begin{array}{l}\text { New Beimen } \\
\text { station }\end{array}$ & UP \\
\hline 1973B & 1973A & disable & Beimen station & UP \\
\hline 1993A & Fire disaster & burn & $\begin{array}{l}\text { Beimen repairing } \\
\text { factory }\end{array}$ & DD \\
\hline 1993B & 1993A & cause & Angry people & SD \\
\hline 1998A & Beimen station & announce & City historic site & UP \\
\hline 1998B & Fire disaster & burn & Beimen station & DD \\
\hline 1998C & Forestry Bureau & repair & Beimen station & UP \\
\hline 1999 & Forestry Bureau & hold & $\begin{array}{l}\text { Forest railway } \\
\text { Festival }\end{array}$ & SD \\
\hline 2001A & Forestry Bureau & repair & Beimen station & UP \\
\hline 2001B & Beimen station & transform & Landscape & SD \\
\hline 2002 & Forestry Bureau & repair & Beimen station & UP \\
\hline 2011 & Beimen station & announce & Cultural tourism & UP \\
\hline
\end{tabular}

Table1. Events of Beimen station from 1723-2013

The cue-point of one timeline means change appear on an object. There will be two state generate by an event. An event presents year and action with rectangle as Figure 5 shows below. States shows name of target (might be initiators or recipients, called pronoun for an instance (as Figure 6). The final result with all events related to Beimen shows as Figure 7 below:

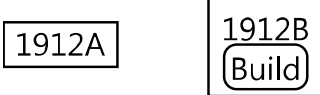

Figure 5. The event present in symbol with year and action information

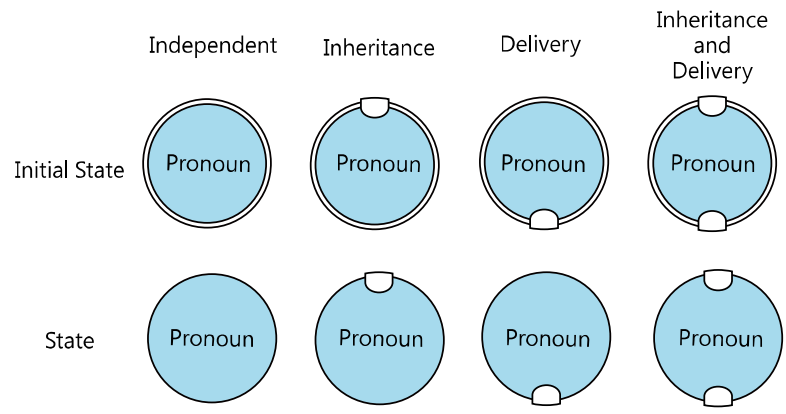

Figure 6. Difference kind of state in event chain

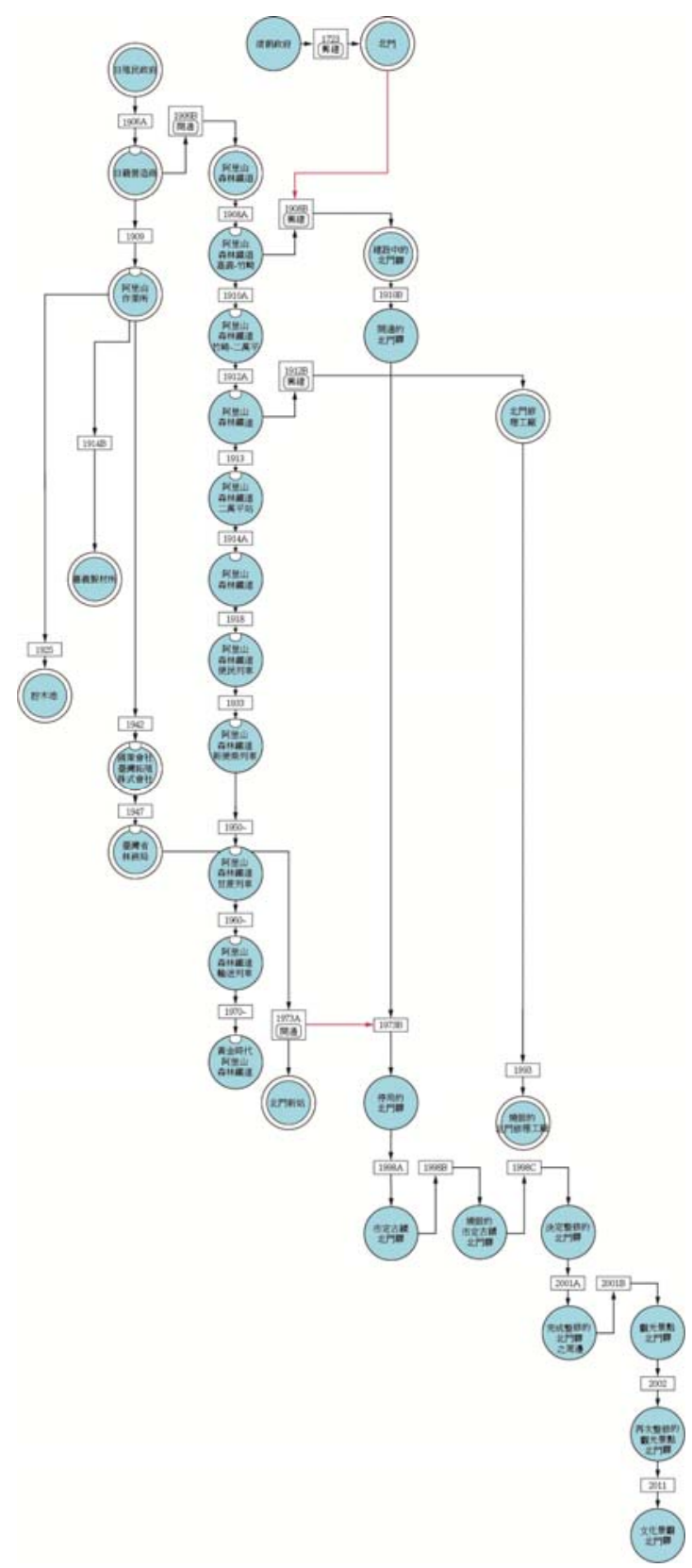

Figure 7. The historic event chain of Beimen station

\section{CONCOLUSION}

Every existing object, like mankind, area, or buildings all have their own timeline. So do a city space. These objects in same city place will generate relationships as time goes by. The historic context analysis research has computational way to observe the subjective perspective of different object. This is the main purpose of this study.

Establishing this historic event database not only supports the historic space research, but also another way to make preservation for culture heritage in digital method. If there is a good interface and right way to use this database, this system may become a local historic education system to pass the right historic context knowledge on, and to make culture of one city flourish. 


\section{REFERENCE}

Cheng, T., 1999, A Process-oriented data model for fuzzy spatial objects. PhD Dissertation, International Institute for Aerospace Survey and Earth Sciences (ITC), Netherlands.

Hsu, T.,W., 2012, Clio: A primary study of the image of historical city, Proc. International Conference on Kansei Engineering and Emotion Research (KEER), Penghu, Taiwan.

Langran, G., Chrisman, N., R., 1988, A framework for temporal geographic information. Cartographica, Vol. 25, No. 3, pp. 1-14.

Leslie, C., Barnes, G., Binford, M., Smith, S. , 2001, A spatiotemporal data model for analyzing the relationship between property ownership changes, land use/land cover and carbon dynamics, Proc. American Congress of Surveying and Mapping Congress. March, Las Vegas, USA.

Peuquet, D., J., Duan, N., 1995. An event-based spatiotemporal data model (ESTDM) for temporal analysis of geographical data. International Journal of Geographical Information Systems, Vol. 9, pp. 7-24.

Yuan, M., 2000, Temporal GIS and spatio-temporal modeling, Proc. the Third International Conference in Integrating GIS and Environmental Modeling, Santa Fe, New Mexico. 